\title{
Cause-specific mortality by occupational skill level in Canada: a 16-year follow-up study
}

\section{Tjepkema, MPH (1); R. Wilkins, MUrb (1, 2); A. Long, MA (3)}

This article has been peer reviewed.

\begin{abstract}
Introduction: Mortality data by occupation are not routinely available in Canada, so we analyzed census-linked data to examine cause-specific mortality rates across groups of occupations ranked by skill level.
\end{abstract}

Methods: A 15\% sample of 1991 Canadian Census respondents aged 25 years or older was previously linked to 16 years of mortality data (1991-2006). The current analysis is based on 2.3 million people aged 25 to 64 years at cohort inception, among whom there were 164332 deaths during the follow-up period. Occupations coded according to the National Occupation Classification were grouped into five skill levels. Age-standardized mortality rates (ASMRs), rate ratios (RRs), rate differences (RDs) and excess mortality were calculated by occupational skill level for various causes of death.

Results: ASMRs were clearly graded by skill level: they were highest among those employed in unskilled jobs (and those without an occupation) and lowest for those in professional occupations. All-cause RRs for men were 1.16, 1.40, 1.63 and 1.83 with decreasing occupational skill level compared with professionals. For women the gradient was less steep: $1.23,1.24,1.32$ and 1.53. This gradient was present for most causes of death. Rate ratios comparing lowest to highest skill levels were greater than 2 for HIV/ AIDS, diabetes mellitus, suicide and cancer of the cervix as well as for causes of death associated with tobacco use and excessive alcohol consumption.

Conclusion: Mortality gradients by occupational skill level were evident for most causes of death. These results provide detailed cause-specific baseline indicators not previously available for Canada.

Keywords: socio-economic status, differential mortality, occupational skill level, Canada

\section{Introduction}

The relationship between an individual's occupation and mortality is well known. Findings from the Whitehall Study showed an inverse social gradient, where rates of coronary heart disease mortality were highest for British civil servants in occupations that required few or no skills, and lowest for those in occupations that required more specific skills, education or other qualifications. ${ }^{1}$ Similar social gradients in mortality have been found in other countries and for other occupations. $^{2-7}$

The association between health and occupation is complex. It has been theorized that occupation affects the health of people through both material and psychosocial pathways as well as by exposure to hazardous conditions or materials at the workplace. $^{7-12}$ For example, people in higher skilled occupations, which tend to be more highly paid, may have better access to material resources that support good health, such as good quality housing and food. Occupation may also have a positive or negative influence on health as a result of the particular demands and rewards associated with different types of work, such as social networks, workbased stress and level of autonomy and control over work conditions. ${ }^{9,10,12-14}$ Exposures to hazardous materials at the workplace also vary by occupation and contribute to differences in mortality rates.

In Canada, large population-based studies examining mortality by occupation are less common than elsewhere. This is in part because the information about usual occupation that is included on death registrations in most provinces tends not to be captured in machine-readable form or coded. However, several record linkagebased follow-up studies have examined the association between occupation and mortality, with each showing higher mortality rates among occupations with lower skill levels. ${ }^{15-18}$ Nevertheless, those results were limited by the scope of the population covered (geographically or by age, sex and/or occupation), small sample size, lack of information about causes of death or a combination of these factors.

Recently, Census data from a $15 \%$ sample of Canadian residents aged 25 years and older were linked to almost 16 years of mortality data. ${ }^{19,20}$ Results based on the first 11 years of follow-up showed that mortality rates overall and for suicide, unintentional injuries and causes amenable to medical care were lower in each successively higher ranked occupational

Author references:

1. Health Analysis Division, Statistics Canada, Ottawa, Ontario, Canada

2. Department of Epidemiology and Community Medicine, University of Ottawa, Ottawa, Ontario, Canada

3. Public Health Agency of Canada, Ottawa, Ontario, Canada

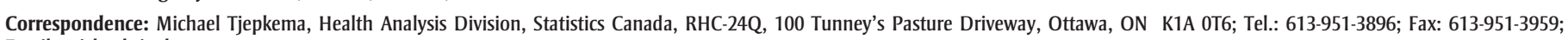
Email: michael.tjepkema@statcan.gc.ca 
skill level. ${ }^{19,21-23}$ However, the findings were not examined across a broad range of detailed causes of death.

The objective of this analysis is to use the full 16 years of linked data to examine mortality rates by occupational skill level among cohort members aged 25 to 64 years at baseline, using the Global Burden of Disease cause of death groupings, and to examine causes of death grouped by three risk factors (smoking, alcohol and drugs) and deaths before age 75 years that were potentially amenable to medical care.

\section{Methods}

\section{Data source}

This is a secondary analysis of data from the 1991 to 2006 Canadian Census Mortality and Cancer Follow-up Study. ${ }^{19,20}$ Individuals were eligible for the cohort ("in-scope") if they were 25 years or older when enumerated by the 1991 Census long-form questionnaire, which excluded residents of institutions such as hospitals, nursing homes and prisons. To be followed for mortality, inscope Census respondents first had to be linked to an encrypted name file abstracted from non-financial tax-filer data. About $80 \%$ of in-scope Census respondents ( $n=2860244$ ) were linked to the name file. A random sample ( $n=125409$ ) was then removed so the final cohort ( $\mathrm{n}=2734$ 835) would be a $15 \%$ sample of the 1991 Canadian population aged 25 years or older, as stipulated in the record linkage protocol. This cohort was then matched to the Canadian mortality database (4 June 1991 to 31 December 2006) using probabilistic record linkage methods primarily based on names and dates of birth. ${ }^{24}$ In the absence of a match to a death registration, follow-up status (alive, dead, emigrated, or lost to followup) could usually be determined from taxfiler data. ${ }^{20}$ Additional details on the construction and contents of the linked file are reported elsewhere. ${ }^{19,20}$ For this study, the analysis was restricted to people aged 25 to 64 years at cohort inception ( $\mathrm{n}=2312$ 400). Almost 2 million people in this age range had a coded occupation, and of those with a coded occupation, $6 \%$ died during the follow-up period. About 313400 cohort members aged 25 to 64 years did not have a coded occupation. Table 1 shows the number of cohort members, person-years at risk and deaths ascertained by occupational skill level, age group and sex.

\section{Definitions}

Occupation was coded based on the kind of work an individual was doing the week prior to the 1991 Census enumeration, or if the person did not have a job that week, based on the job of longest duration since 1 January 1990. Respondents were asked to specify the kind of work they were doing and the most important activities or duties of their job. ${ }^{25}$ This information was then coded to an occupational category based on the 1990 National Occupational Classification. $^{26}$ The skill level of each occupation was then assigned to one of the following categories: professional, managerial, skilled/technical/supervisory, semi-skilled or unskilled. Skill level was broadly defined as the amount and type of education and training required to enter and perform the duties of an occupation. In the National Occupational Classification, managerial occupations are not assigned a skill level because factors other than education and training (such as previous experience) are often more significant determinants of managerial employment. For the purposes of this study, managers were ranked between professional and supervisory occupations. People who had not worked within the reference period were retained as a separate "no occupation" category, which included long-term unemployed, mature students, stay-at-home parents, people who were unable to work, retirees and others who had not worked in the reference period.

\section{Analytical techniques}

For each cohort member, person-days of follow-up were calculated from the day of the Census (4 June 1991) to the date of death, date of emigration or the last day of the study period (31 December 2006). Person-days of follow-up were divided by 365.25 to obtain person-years at risk. Age at baseline-, sex- and occupational skill level-specific mortality rates by 5 -year age groups were used to calculate age-standardized mortality rates (ASMRs), using the cohort population structure (personyears at risk), both sexes together, as the standard population.

Relative inequalities were assessed by rate ratios (RRs) and percent excess mortality. RRs were calculated by dividing the ASMR for a specific occupation level (unskilled, semi-skilled, skilled/technical/supervisory, managerial) by the ASMR for those in professional occupations. RRs greater than one indicate an increased mortality risk. Percent excess mortality was calculated by subtracting the ASMR for those in professional occupations from the ASMR for all cohort members with any occupation, then dividing by the ASMR for all occupationally-active cohort members and multiplying by 100 .

Absolute inequalities were assessed by rate differences (RDs) and absolute excess mortality. RDs were calculated by subtracting the ASMR for unskilled, semiskilled, skilled/technical/supervisory, and managerial occupations, respectively, from the ASMR for those in professional occupations. RDs greater than zero indicate excess mortality. Absolute excess mortality was calculated by subtracting the ASMR of those in professional occupations from the ASMR for all cohort members with an occupation. The difference represents the number of deaths (per 100 000) that could hypothetically have been avoided if all occupationally active cohort members had experienced the mortality rates of those in professional occupations.

For ASMRs, RRs and RDs, 95\% confidence intervals (CIs) were calculated according to previously described methods. ${ }^{27}$

Mortality data included underlying cause of death coded based on the World Health Organization's ICD-9 (International Classification of Diseases, 9th Revision ${ }^{28}$ ) for deaths prior to 2000, and on ICD-10 (International Classification of Diseases, 10th Revision ${ }^{29}$ ) for deaths between 2000 and 2006. Deaths were grouped by Global Burden of Disease categories. ${ }^{30}$ Using conservative definitions, causes of death 
TABLE 1

Cohort members, person-years at risk and deaths ascertained, by age group, sex and occupational skill level at baseline, Canada, 1991-2006

\begin{tabular}{|c|c|c|c|c|c|c|}
\hline & \multicolumn{3}{|c|}{ Men } & \multicolumn{3}{|c|}{ Women } \\
\hline & $\begin{array}{c}\text { Cohort } \\
\text { members, n }\end{array}$ & PYAR & $\begin{array}{c}\text { Deaths } \\
\text { ascertained, } n\end{array}$ & $\begin{array}{c}\text { Cohort } \\
\text { members, n }\end{array}$ & PYAR & $\begin{array}{c}\text { Deaths } \\
\text { ascertained, } n\end{array}$ \\
\hline \multicolumn{7}{|l|}{ Age $25-64$ years (at baseline) } \\
\hline No occupation & 85000 & 1112820 & 25469 & 228400 & 3319420 & 24048 \\
\hline All occupations & 1073900 & 15872090 & 79176 & 925100 & 13924000 & 35639 \\
\hline Professional & 140300 & 2070010 & 6946 & 158100 & 2381480 & 4445 \\
\hline Skilled/technical/supervisory & 375600 & 5573320 & 27508 & 252300 & 3805080 & 9411 \\
\hline Semi-skilled & 294500 & 4351650 & 23592 & 352500 & 5304770 & 14241 \\
\hline Unskilled & 110100 & 1609130 & 11110 & 97800 & 1466250 & 5137 \\
\hline \multicolumn{7}{|l|}{ Age 25-44 years (at baseline) } \\
\hline No occupation & 25000 & 353230 & 2493 & 118600 & 1764980 & 3854 \\
\hline Skilled/technical/supervisory & 246000 & 3700050 & 7010 & 177700 & 2693240 & 3068 \\
\hline Semi-skilled & 200300 & 3004390 & 6767 & 247300 & 3739050 & 4655 \\
\hline Unskilled & 70400 & 1050410 & 2725 & 63100 & 952800 & 1433 \\
\hline \multicolumn{7}{|l|}{ Age 45-64 years (at baseline) } \\
\hline No occupation & 60100 & 759590 & 22976 & 109700 & 1554440 & 20194 \\
\hline All occupations & 373400 & 5382570 & 58602 & 278600 & 4151440 & 24070 \\
\hline Professional & 47400 & 696330 & 5107 & 44100 & 663310 & 2792 \\
\hline Managerial & 62300 & 907000 & 7787 & 20000 & 297120 & 1645 \\
\hline Skilled/technical/supervisory & 129700 & 1873270 & 20498 & 74600 & 1111840 & 6343 \\
\hline
\end{tabular}

Source: 1991-2006 Canadian Census Mortality and Cancer Follow-up Study. ${ }^{20}$

Abbreviation: PYAR, person-years at risk.

were grouped by behavioural health risk factors, namely smoking-related diseases ${ }^{2}$ (e.g. cancers of buccal cavity, pharynx, esophagus, larynx, trachea, bronchus, lung, chronic obstructive pulmonary disease), alcohol-related diseases ${ }^{2}$ (e.g. alcoholic psychosis, alcoholic cirrhosis of liver and pancreas, accidental poisoning by alcohol) and drug-related diseases ${ }^{31}$ (e.g. accidental poisoning by narcotics and other drugs, drug use disorders). We also examined deaths among those aged less than 75 years that were potentially amenable to medical intervention, such as deaths due to cerebrovascular disease, hypertension, breast cancer and pneumonia/influenza. ${ }^{2,32}$ The detailed definitions of the cause groupings are available on request.
The Canadian Census Mortality and Cancer Follow-up Study was approved by the Statistics Canada Policy Committee, after consultations with the Statistics Canada Confidentiality and Legislation Committee, the Data Access and Control Services Division, and the Federal Privacy Commissioner.

\section{Results}

Of the 2.3 million cohort members aged 25 to 64 years at cohort inception, $7 \%$ of men and $20 \%$ of women had no occupation coded by the census. Of the 2 million cohort members with a reported occupation, $13 \%$ of men and $17 \%$ of women were in professional occupations; $14 \%$ of men and $7 \%$ of women were in manage- rial positions; $35 \%$ of men and $27 \%$ of women were in skilled, technical or supervisory occupations; and $27 \%$ of men and $38 \%$ of women were in semi-skilled occupations. The remaining $10 \%$ for men and $11 \%$ for women were in unskilled occupations (see Table 1).

As shown in Table 2, for cohort members of both sexes, ASMRs for all causes of death were graded by occupational skill level, with higher mortality rates for those in less skilled occupations. Compared with men in professional occupations, the RRs were 1.16 for men in managerial occupations, 1.40 for men in skilled, technical or supervisory occupations, 1.63 for men in semi-skilled occupations and 1.83 for men in unskilled occupations. For women, the 
TABLE 2

Number of deaths, age-standardized mortality rates per 100000 person-years at risk, rate ratios and rate differences, by occupational skill level and sex, cohort members aged 25 to 64 years at baseline, Canada, 1991-2006

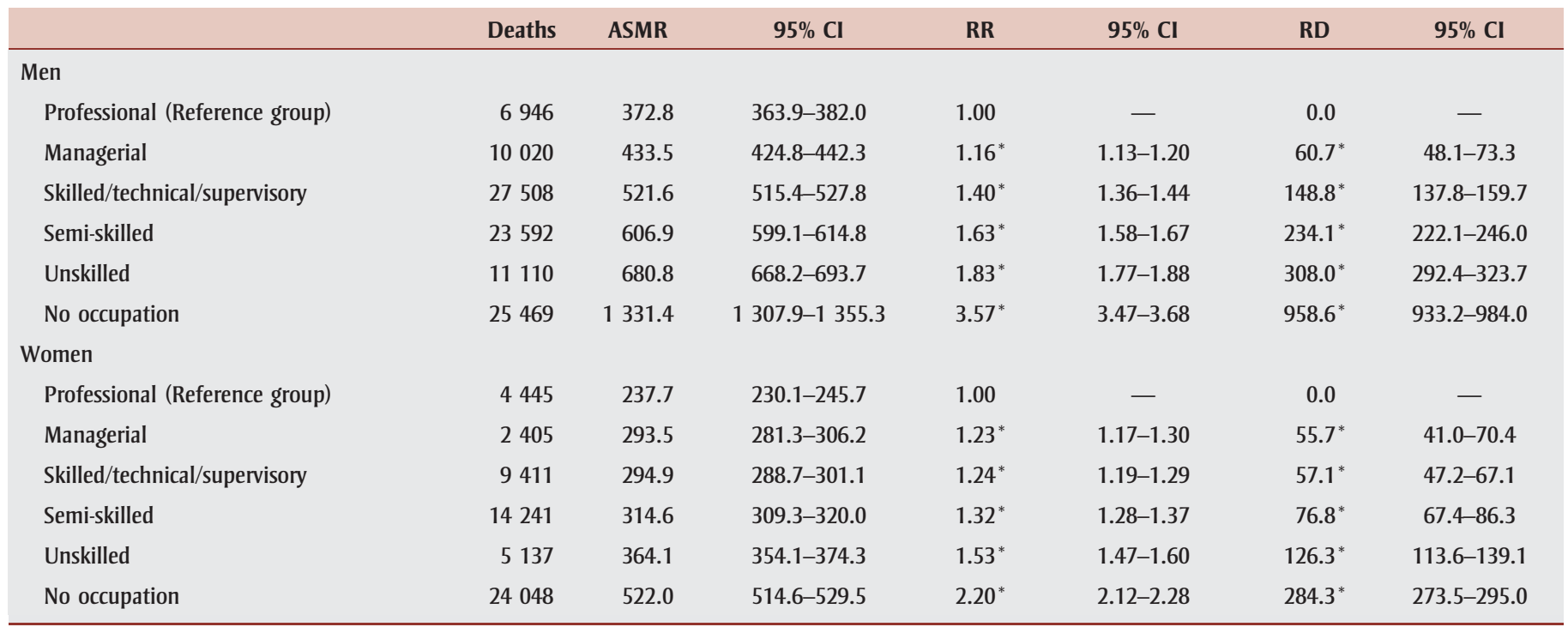

Source: 1991-2006 Canadian Census Mortality and Cancer Follow-up Study. ${ }^{20}$

Abbreviations: ASMR, age-standardized mortality rate; $\mathrm{Cl}$, confidence interval; $\mathrm{RD}$, rate difference; RR, rate ratio.

Notes: Reference population (person-years at risk) for age standardization was taken from internal cohort age distribution (5-year age groups).

— : not applicable.

* Significantly different from Professional $(p<.05)$.

corresponding RRs were $1.23,1.24,1.32$ and 1.53 , respectively. For those without an occupation, the RRs were 3.57 for men and 2.20 for women. The RD comparing professional to other occupational skill levels was greatest for those in unskilled occupations (308 per 100000 for men; 126 per 100000 for women).

The mortality gradient by occupational skill level differed by cause of death groupings (Tables 3 and 4). For men, RRs comparing unskilled to professional occupations were greater than 2 for deaths due to alcohol use disorders (3.94), chronic obstructive pulmonary disease (2.74), trachea, bronchus and lung cancers (2.69), unintentional injuries (2.56), cirrhosis (2.44), diabetes mellitus (2.24) and suicide (2.11) (Table 3). By contrast, the gradient was reversed for HIV/AIDS deaths (0.68). The RR for dementias was not statistically significant (1.17).

For women, RRs comparing unskilled to professional occupations were greater than 2 for deaths due to cervix uteri cancer (3.19), diabetes mellitus (2.54), alcohol use disorders (2.42), ischemic heart disease (2.29), trachea, bronchus and lung cancers (2.24), chronic obstructive pulmonary disease (2.06) and cirrhosis (2.05) (Table 4). By contrast, the gradient was reversed for breast cancer (0.85). RRs were not statistically significant for stomach cancer (1.35), dementias (1.28), respiratory infections (1.24), colon and rectal cancers (1.13) or ovarian cancer (0.91).

The percentage excess mortality related to occupational skill level is shown in the last column of Tables 3 and 4. If all occupationally active cohort members had experienced the ASMRs of those in professional occupations, then the all-cause ASMR would have been $29 \%$ lower for men and $21 \%$ lower for women, representing 155 and 64 fewer deaths per 100000 person-years at risk, respectively. About half of this excess mortality was due to deaths from cardiovascular diseases and cancers of the trachea, bronchus and lung.

Causes of death were also grouped by risk factor (smoking-related diseases, alcoholrelated diseases and drug-related dis- eases). For smoking-related diseases, the RR was 2.61 for men in unskilled occupations compared with those in professional occupations (Table 3). For women, the corresponding RR was 2.15 (Table 4). The RRs for alcohol- and drug-related disease deaths were also elevated (3.41 and 2.68 for men; 2.35 and 2.07 for women). The RRs for deaths prior to age 75 years that were potentially amenable to medical intervention were 1.45 for men and 1.11 for women.

Table 5 presents ASMRs for all causes and for selected cause of death groupings, by occupational skill level, age group at baseline and sex. In terms of RRs, the mortality gradient by occupational skill level was slightly steeper for those aged 25 to 44 years (at baseline) compared with those aged 45 to 64 years. For men, the RR was 2.19 at ages 25 to 44 years compared with 1.72 for those aged 45 to 64 years. For women, the RR was 1.65 at ages 25 to 44 years compared with 1.49 at ages 45 to 64 years. Although RRs across occupational skill levels were higher in the 25- to 44-year age group, absolute differences were greater for those aged 45 to 64 years. 
TABLE 3

Age-standardized mortality rates per 100000 person-years at risk, rate ratios and excess mortality for selected causes of death, by occupational skill level, male cohort members aged 25 to 64 years at baseline, Canada, 1991-2006

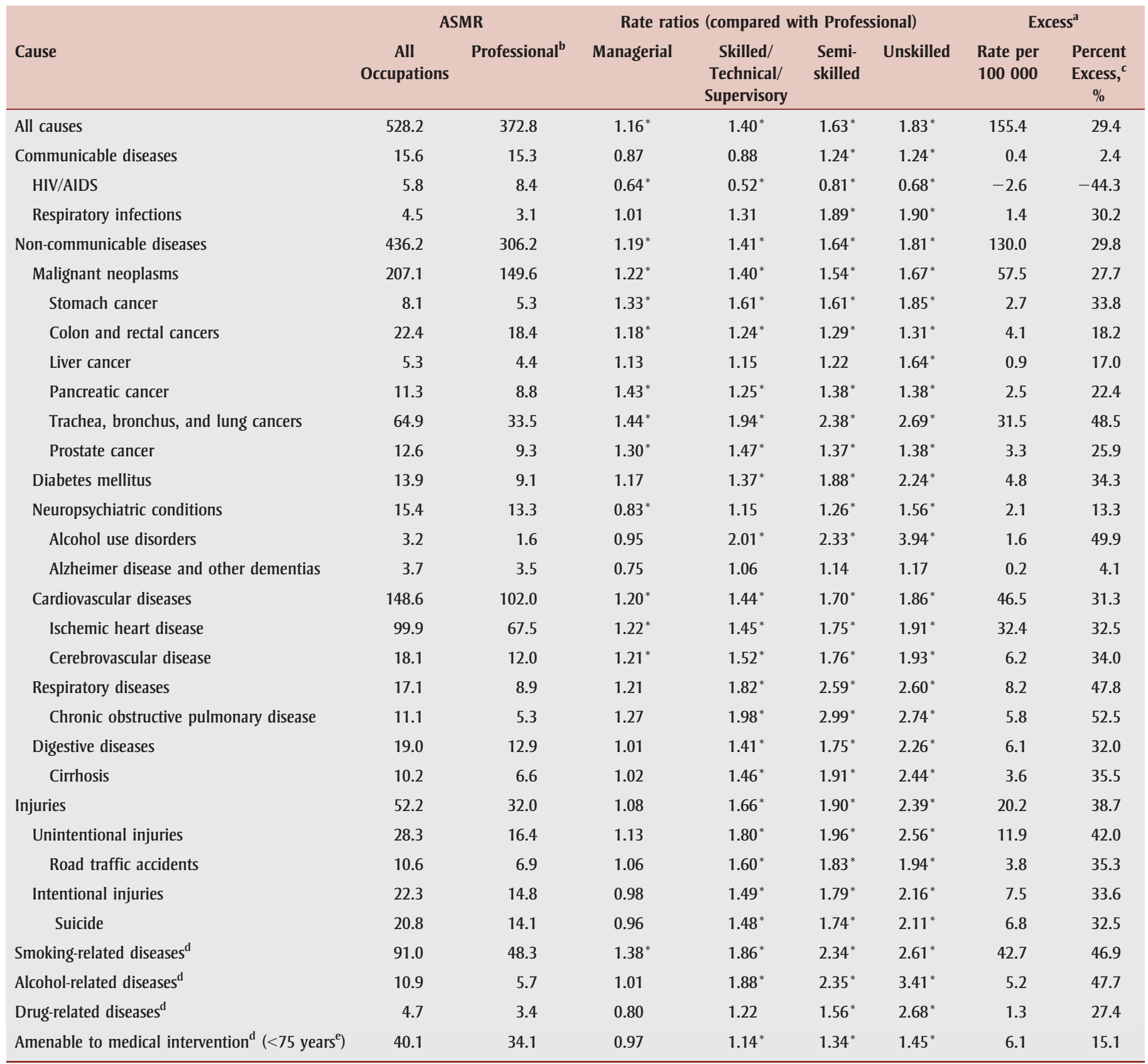

Source: 1991-2006 Canadian Census Mortality and Cancer Follow-up Study. ${ }^{20}$

Abbreviation: ASMR, age-standardized mortality rate.

Note: Reference population (person-years at risk) for age-standardization was taken from the internal cohort age distribution (5-year age group).

${ }^{a}$ Excess (All occupations - Professional).

${ }^{\mathrm{b}}$ Reference group.

c Percent excess [100 $\times$ (All occupations - Professional)/All occupations].

d Detailed ICD codes are available on request.

${ }^{\text {e }}$ Deaths before age 75 years that were potentially amenable to medical intervention, e.g. due to cerebrovascular disease, hypertension, breast cancer and pneumonia/influenza.

* Significantly different from rate for Professional $(p<.05)$. 
TABLE 4

Age-standardized mortality rates per 100000 person-years at risk, rate ratios and excess mortality for selected causes of death, by occupational skill level, female cohort members aged 25 to 64 years at baseline, Canada, 1991-2006

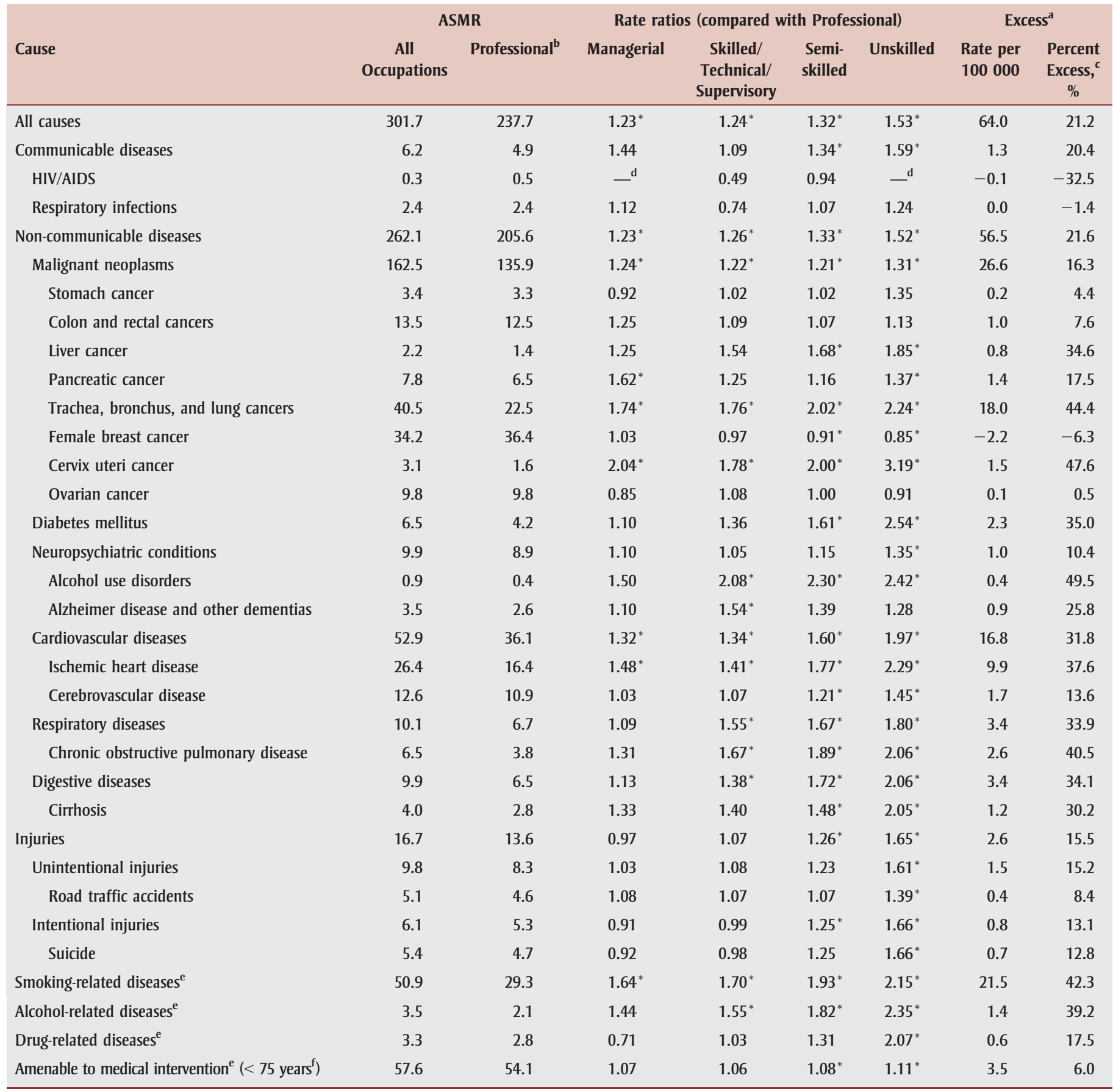

Source: 1991-2006 Canadian Census Mortality and Cancer Follow-up Study. ${ }^{20}$

Abbreviation: ASMR, age-standardized mortality rate.

Note: Reference population (person-years at risk) for age-standardization was taken from the internal cohort age distribution (5-year age group).

${ }^{\text {a }}$ Excess (All occupations - Professional).

b Reference group.

c Percent excess [100 $\times$ (All occupations - Professional)/All occupations].

d Suppressed due to Statistics Canada disclosure rules.

e Detailed ICD codes are available on request.

${ }^{\mathrm{f}}$ Deaths before age 75 years that were potentially amenable to medical intervention, e.g. due to cerebrovascular disease, hypertension, breast cancer and pneumonia/influenza.

* Significantly different from rate for Professional $(p<.05)$. 
TABLE 5

Age-standardized mortality rates per 100000 person-years at risk, rate ratios and excess mortality for selected causes of death, by occupational skill level, age group, cohort members aged 25 to 64 years at baseline, Canada, 1991-2006

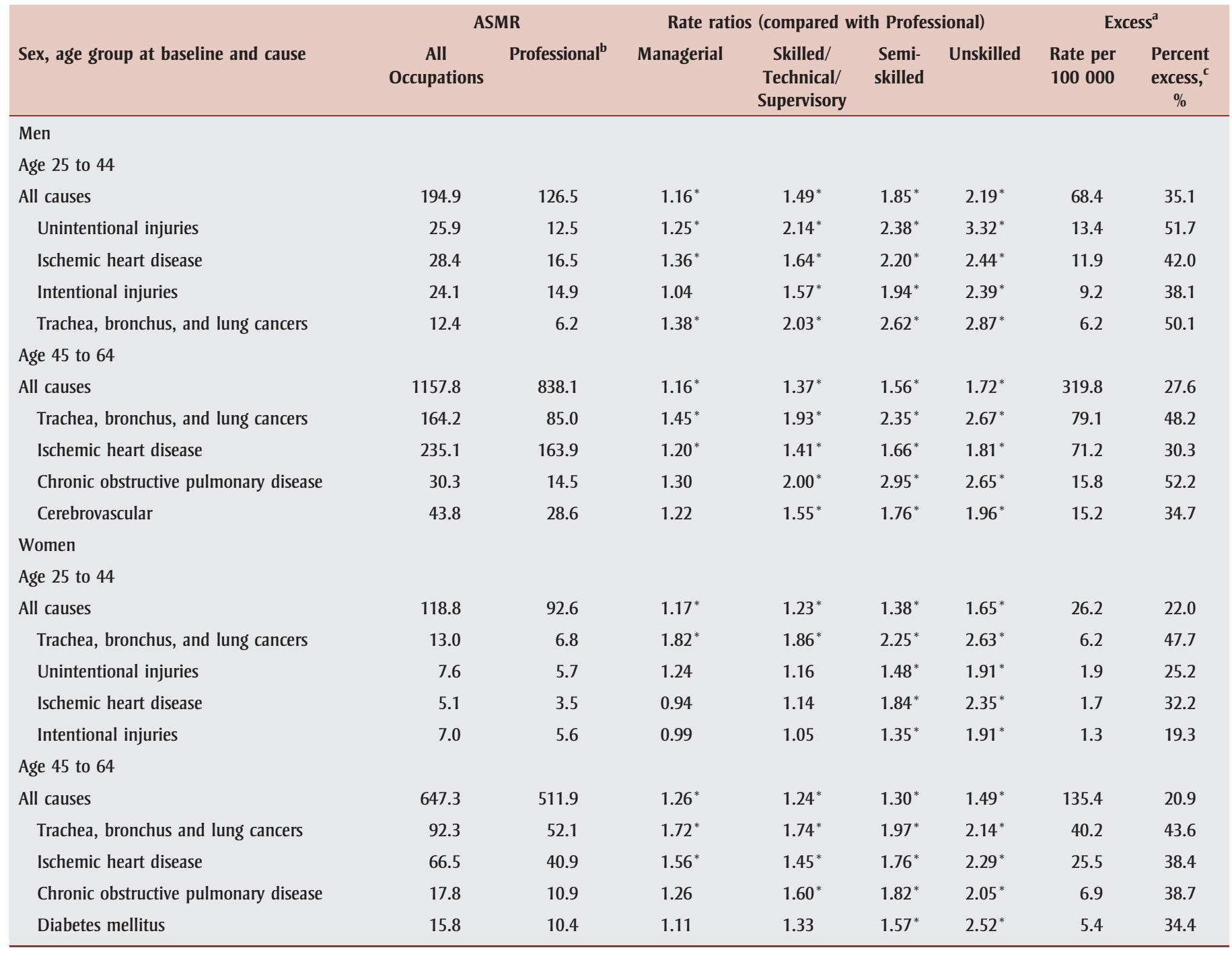

Source: 1991-2006 Canadian Census Mortality and Cancer Follow-up Study. ${ }^{20}$

Abbreviations: ASMR, age-standardized mortality rate; RR, rate ratio.

Note: Reference population (person-years at risk) for age-standardization was taken from the cohort age distribution (5-year age group).

a Excess (All occupations - Professional).

b Reference group ( $\mathrm{RR}=1.00$ not shown).

c Percent excess [100 $\times$ (All occupations - Professional)/All occupations].

* Significantly different from rate for Professional $(p<.05)$.

The causes of death that contributed the most to excess mortality differed somewhat by sex and age group. For cohort members aged 25 to 44 years, unintentional injuries were the largest contributor for men, while cancers of the trachea, bronchus and lung were the largest contributor for women. For both men and women aged 45 to 64 , cancers of the trachea, bronchus and lung were the largest contributor.

\section{Discussion}

Substantial mortality gradients by occupational skill level were evident for most causes of death for both men and women. If all cohort members with an occupation had experienced the age-specific mortality rates of those in professional occupations, then the all-cause ASMR would have been $29 \%$ lower for men and $21 \%$ lower for women. For men, this would be equiva- lent to eliminating all deaths from cardiovascular diseases, while for women it would be equivalent to eliminating all deaths from both cardiovascular and respiratory diseases.

With few exceptions, mortality rates for the causes of death examined were associated with occupational skill level. However, the gradient and strength or magnitude of the association varied 
considerably by cause of death. RRs were highest for causes of death more closely associated with health risk behaviours (such as smoking and excessive alcohol consumption) and lowest for causes not closely associated with those behaviours (such as breast and prostate cancer), and causes where less is known regarding prevention. Studies from Sweden ${ }^{6}$ and the United States $^{33}$ have demonstrated similar results. Phelan et al. ${ }^{33}$ found that socio-economic status was less strongly associated with causes of death that have low preventability. Although the pathways between occupation and health are complex, acting at both individual and ecological levels, ${ }^{34,35}$ causes of death that are more preventable tended to demonstrate a closer association with socioeconomic status. From an individual perspective, this may be in part because people with greater resources may be better able to adapt their behaviour to take advantage of new knowledge about risk factors or preventive measures. ${ }^{36}$

Reducing socio-economic inequalities in health is an explicit objective of health policies in Canada. ${ }^{37} \mathrm{~A}$ strength of this study is that results are based on a large, broadly representative sample of Canadians aged 25 to 64 years at the time of the 1991 census. The large sample size allowed for analysis of mortality differences by occupational skill level within detailed cause of death groupings and for the detection of small effects. However, a person's occupation was only known at cohort inception (1991) and could have changed during the follow-up period (1991-2006); as such, the listed occupation may not necessarily represent a person's long-term occupation skill level.

This study was not intended to assess the relative importance of direct and indirect effects of occupation on mortality-for example, the extent to which differences in mortality by occupational skill level may be explained by associated differences in education and income. The data also did not include information on risk factors (such as smoking) and thus may have overestimated the direct effect of occupation on mortality. Nevertheless, other research concludes that socioeconomic differences in various health outcomes (including mortality) largely persist even after controlling for behavioural risk factors. ${ }^{38-40}$

\section{Conclusion}

This is the first time that detailed causespecific mortality rates by occupational skill level have been examined for Canada across a wide range of causes of death. Results from this study confirm what is known about mortality gradients by occupational skill level in the international literature, and help to quantify the importance of such inequalities in Canada.

We found that most causes of death showed substantial differences in mortality rates by occupational skill level. Causes of death that were more preventable, including those more closely associated with smoking and excessive alcohol consumption, tended to have steeper gradients compared with less preventable causes. With the extension of the 19912006 Canadian Census Mortality Study to include linkage to cancer incidence data, future work could examine the nature and extent of inequalities in cancer incidence and survival.

\section{Acknowledgements}

We are grateful to Canada's provincial and territorial registrars of vital statistics, who provided the death data used in this study; to Statistics Canada, which conducted the 1991 Census; and to the people of Canada, whose answers to the long-form census questionnaire provided the basis for these analyses.

There were no competing interests.

Funding for this analysis was provided by the Public Health Agency of Canada. Funding for the creation of the Canadian Census Mortality Follow-up Study was provided by the Canadian Population Health Initiative of the Canadian Institute of Health Information (original study), the Healthy Environment and Consumer Safety Branch of Health Canada (study extensions) and the Health Analysis Division of Statistics Canada.

\section{References}

1. Marmott MG, Bosma H, Hemingway $H$, Brunner E, Stansfeld S. Contribution of job control and other risk factors to social variations in coronary heart disease incidence. Lancet. 1997;350(9073):235-9.

2. Mackenbach JP, Stirbu I, Roskam AJ, et al. Socioeconomic inequalities in health in 22 European countries. N Engl J Med. 2008;358(23):2468-81.

3. Langford A, Johnson B. Trends in social inequalities in male mortality, 2001-08. Intercensal estimates for England and Wales. Health Stat Q. 2010;(47):5-32.

4. Saurel-Cubizolles MJ, Chastang JF, Menvielle G, Leclerc A, Luce D; EDISC group. Social inequalities in mortality by cause among men and women in France. J Epidemiol Community Health. 2009;63(3): 197-202.

5. Weires M, Bermejo JL, Sundquist K, Sundquist J, Hemminki K. Socio-economic status and overall and cause-specific mortality in Sweden. BMC Public Health. 2008;8:340.

6. Erikson R, Torssander J. Social class and cause of death. Eur $\mathrm{J}$ Public Health. 2008;18(5):473-8.

7. Commission on Social Determinants of Health. Closing the gap in a generation: health equity through action on the social determinants of health: final report of the Commission on Social Determinants of Health. Geneva (CH): World Health Organization; 2008 [cited 2012 Aug 15]. Available from: http://whqlibdoc.who.int /publications/2008/9789241563703_eng.pdf

8. Stringhini S, Dugravot A, Shipley M, et al. Health behaviours, socioeconomic status, and mortality: further analyses of the British Whitehall II and the French GAZEL prospective cohorts. PLoS Med. 2011;8(2): e1000419.

9. Galobardes B, Shaw M, Lawlor DA, Lynch JW, Davey Smith G. Indicators of socioeconomic position (part 1). J Epidemiol Community Health. 2006;60(1):7-12. 
10. Galobardes B, Shaw M, Lawlor DA, Lynch JW, Davey Smith G. Indicators of socioeconomic position (part 2). J Epidemiol Community Health. 2006;60(2):95-101

11. Lynch J, Kaplan G. Socioeconomic position. In: Berkman LF, Kawachi I, eds. Social Epidemiology. New York: Oxford University Press; 2000. p.13-35.

12. Mikkonen J, Raphael D. Social determinants of health: the Canadian facts. Toronto: York University School of Health Policy and Management; 2010 [cited 2012 Aug 15]. Available from: http://www .thecanadianfacts.org/The_Canadian_Facts .pdf

13. Karasek R, Baker D, Marxer F, Ahlbom A, Theorell T. Job decision latitude, job demands, and cardiovascular disease: a prospective study of Swedish men. Am J Public Health. 1981;71(7):694-705.

14. Shields M. Stress and depression in the employed population. Health Rep. 2006; 17(4):11-29.

15. Aronson KJ, Howe GR, Carpenter M, Fair ME. Surveillance of potential associations between occupations and causes of death in Canada, 1965-91. Occup Environ Med. 1999;56(4):265-9.

16. Chen J, Beavon D, Wilkins R. Mortality of retired public servants in Canada. Proceedings of the Social Statistics Section, Annual Meeting of the American Statistical Association. Chicago (IL): American Statistical Association; 1996. p.86-91.

17. Wigle DT, Semenciw RM, Wilkins K, et al. Mortality study of Canadian male farm operators: non-Hodgkin's lymphoma mortality and agricultural practices in Saskatchewan. J Natl Cancer Inst. 1990;82(7):575-82.

18. Mustard CA, Derksen S, Berthelot JM, Wolfson M, Roos LL. Age-specific education and income gradients in morbidity and mortality in a Canadian province. Soc Sci Med. 1997;45(3):383-97.

19. Wilkins R, Tjepkema M, Mustard C, Choinière R. The Canadian census mortality follow-up study, 1991 through 2001. Health Rep. 2008;19(3):25-43.
20. Peters PA, Tjepkema M. 1991-2011 Canadian Census Mortality and Cancer Follow-up Study. Proceedings of Statistics Canada Symposium 2010. Social Statistics: The Interplay among Censuses, Surveys and Administrative Data. 2011:150-6. Ottawa (ON): Statistics Canada. [Statistics Canada, Catalogue no. 11-522-XCB].

21. Mustard CA, Bielecky A, Etches J, et al. Suicide mortality by occupation in Canada, 1991-2001. Can J Psychiatry. 2010;55(6): $369-76$.

22. Mustard CA, Bielecky A, Etches J, et al. Avoidable mortality for causes amenable to medical care, by occupation in Canada, 1991-2001. Can J Public Health. 2010; 101(6):500-6.

23. Burrows S, Auger N, Gamache P, Hamel D. Individual and area socioeconomic inequalities in cause-specific unintentional injury mortality: 11-year follow-up study of 2.7 million Canadians. Accid Anal Prev. 2012;45:99-106.

24. Fair M. Generalized Record Linkage System - Statistics Canada's record linkage software. Austrian J Stat. 2004;33(1\&2):37-53.

25. Statistics Canada. 1991 Census dictionary. Ottawa (ON): Supply and Services Canada; 1992. [Statistics Canada, Catalogue No.: 92-301E].

26. Employment and Immigration Canada. National Occupational Classification: occupational descriptions. Ottawa (ON): Canada Communications Group; 1993.

27. Spiegelman M. Introduction to Demography. Revised edition. Cambridge (MA): Harvard University Press; 1968.

28. World Health Organization. Manual of the international statistical classification of diseases, injuries and causes of death. 9th rev. Geneva (CH): World Health Organization; 1977.

29. World Health Organization. International statistical classification of diseases and related health problems, 10th rev. Geneva (CH): World Health Organization; 1992.

30. World Health Organization. The global burden of disease: 2004 update. Geneva (CH): World Health Organization; 2008.
31. Deaths related to drug poisoning: England and Wales, 1999-2003. Health Stat Q. 2005 Spring;(25):52-9.

32. Stirbu I, Kunst AE, Bopp $M$, et al. Educational inequalities in avoidable mortality in Europe. J Epidemiol Community Health. 2010;64(10):913-20.

33. Phelan JC, Link BG, Diez-Roux A, Kawachi I, Levin B. "Fundamental causes" of social inequalities in mortality: a test of the theory. J Health Soc Behav. 2004;45(3): 265-85.

34. Krieger N. Workers are people too: societal aspects of occupational health disparities an ecosocial perspective. Am J Ind Med. 2010;53(2):104-15.

35. Lipscomb HJ, Loomis D, McDonald MA, Argue RA, Wing S. A conceptual model of work and health disparities in the United States. Int J Health Serv. 2006(1);36:25-50.

36. Phelan JC, Link BG, Tehranifar P. Social conditions as fundamental causes of health inequalities: theory, evidence, and policy implications. J Health Soc Behav. 2010; 51(Suppl):S28-40.

37. Chief Public Health Officer's report on the state of public health in Canada, 2008: Addressing health inequalities. Ottawa (ON): Minister of Health, 2008. [Health Canada, Catalogue No.: HP2-10/2008].

38. McGrail KM, van Doorslaer E, Ross NA, Sanmartin C. Income-related health inequalities in Canada and the United States: a decomposition analysis. Am J Public Health. 2009;99(10):1856-63.

39. Kim HJ, Ruger JP. Socioeconomic disparities in behavioral risk factors and health outcomes by gender in the Republic of Korea. BMC Public Health. 2010;10:195.

40. Lantz PM, House JS, Lepkowski JM, Williams DR, Mero RP, Chen J. Socioeconomic factors, health behaviors, and mortality: results from a nationally representative prospective study of US adults. JAMA. 1998;279(21):1703-8. 